\title{
A Case Study on the Effect of Ergonomics Program in Shipbuilding Industry during the Last Ten Years
}

\author{
Hyun-Wook Jeong ${ }^{1}$, Yu-Chang Kim ${ }^{2}$ \\ ${ }^{1}$ HSE Operation Team, Daewoo Shipbuilding and Marine Engineering, Geoje, 656-714 \\ ${ }^{2}$ Department of Industrial Management Engineering, Dong-eui University, Busan, 614-714
}

\begin{abstract}
Objective: The Work-related musculoskeletal disorders(WMSDs) have been a problem on industrial occupational safety and health in Korean shipyard industry. It has been a big social problem. Background: As a result, Korean government enacted a law to prevent musculoskeletal disorders at work and some major companies have already implemented an ergonomics program. Method: This paper presents a study on the effect of an ergonomics program in a Korean shipbuilding company during the last ten years. Conclusion: The Incidence of WMSDs, the worker's compensation cost and the lost time were decreased after implementation of the ergonomics program. Application: The results of the publishing will help efficient operation of MSDs prevention activity in other companies.
\end{abstract}

Keywords: Shipyard industry, Musculoskeletal Disorders(MSDs), Ergonomics program, Shipbuilding company

\section{Introduction}

1990년대 중반 한국통신공사 전화교환원들의 경견완장해 집단발병을 계기로 알려진 작업관련 근골격계질환은 2000 년대 초반부터 급격히 증가하기 시작하였으며, 조선(조선업), 중공업, 자동차(자동차 제조업) 등 대기업 사업장에서는 노 동단체의 요구와 맞물려 집단적인 산업재해 요양신청 등으 로 인해 사회적인 문제로까지 비화되었다(Kim, 2003).

이에 따라 2003년 4월 노동부는 단순반복 작업, 인체에 과도한 부담을 주는 작업에 대해 근골격계질환을 예방하기 위해 "유해요인조사", "근골격계질환 예방 프로그램"의 시행 등 산업안전보건에 관한 규칙을 개정하여 2003년 8월부터 시행하였다.

특히 조선산업(조선업)의 경우 전통적인 제조업의 특성 외 에 다른 특성과 다양한 유해요인에 의해 지속적으로 근골격 계질환이 발생하고 있으며, 현재 작업자들의 고령화로 인한 요인까지 더해지고 있는 실정이다(Kim and Chang, 2006).
본 연구에서는 이러한 조선산업(조선업)의 특성과 조선산 업(조선업)에서의 근골격계질환을 예방하기 위한 2001년부 터 10년간의 활동 경과 및 효과를 살펴보고, 앞으로의 방향 에 대해 논의하고자 한다.

\section{The Characteristics of Shipyard Industry and MSDs}

조선업에서의 근골격계질환 발생을 이해하기 위해, 우선 조선업의 특징을 살펴보면 다음과 같다.

첫째 조선업은 선박의 발주 량(발주량)에 따라 작업 물량 이 결정되고, 수주 량(수주량), 다양한 선종, 개별 프로젝트 에 따라 작업량의 변화가 심할 뿐만 아니라, 대형 건조물을 다루는 작업특성상 옥외작업이 많아 날씨에 영향이 많고 인 도시점 등에 따라 작업량이 집중되는 등의 특성을 나타낸다 (Pyo and Jeong, 2007). 
둘째, 가설 구조물이 많고, 임시 작업통로의 확보, 개구부 관리, 추락방지조치, 밀폐공간 작업, 상시적인 소음노출, 대 형 기계/기구에 의한 작업 등 작업방법적인 측면과, 발주 및 하도급에 의한 작업 진행, 여러 협력업체의 작업수행 등 형 태로는 건설업종과 유사한 관리 형태를 나타내기도 한다.

셋째, 제조업 고유의 특성인 동일한 장소에서 유사한 작업 에 장기간 종사하는 근로자가 많은 점에서는 전형적인 제조 업의 특성을 보이기도 한다.

이러한 특성으로 인하여, 부적절한 작업자세 및 무리한 작 업, 반복작업 등으로 인한 근골격계질환 발생 위험성이 높은 편이다(Kim et al., 2006).

2002 2004년 급격히 발생했던 근골격계질환은 관련법 규 제정, 제도 정비, 노사간의 협력을 통한 예방활동의 노력 으로 꾸준히 감소하였으나, 앞에서 열거한 특성을 가진 조선 업에서의 근골격계질환은 전 생산 공정 및 직무에서 발생하 고 있으며, 다양한 신체부위의 질환들이 나타나고 있다.

\section{Ergonomics Program}

앞에서 살펴본 봐(바) 와 같이 조선산업(조선업)에서의 근 골격계질환은 복합적인 요인에 의해 매우 다양한 형태로 발 생되고 있다. 또한, 노동집약적인 산업, 직업병 인정범위의 확대 및 고령화, 개인의 건강에 대한 관심 증가 등의 내부환 경과 예방규제(법률) 강화, 사회적인 인식 변화 등 외부적인 환경이 종합적으로 반영되어 단순한 휴업치료 수준 및 현장 의 문제점 개선 측면을 넘어 각종 유해요인을 체계적으로 관 리하여 예방하려는 프로그램이 필요하다.

그래서 D사에서는 2002년 UAW-Ford Ergonomics Process를 기반으로 하여 대한인간공학회와 공동으로 조선 업체 최초의 인간공학 프로그램을 개발하게 된다. 인간공학 프로그램은 작업개선 우선순위확인, 작업스트레스 평가, 해 결방안의 개발/선택, 해결방안의 실행, 사후관리 및 프로그 램 평가의 단계로 진행되며, 시범부서에 적용하여 전사확대 방안을 모색하였다(Kim and Chang, 2010).

또한, 2002년 초에 발생한 근골격계질환의 집단요양 등의 노사간의 분쟁에 대해 지속적으로 협의하였으며, 이에 대해 노사간 공동으로 "산업재해 예방 및 재활지원 프로그램"을 추진하자는 취지에서 합의를 이끌어내 특별협약서를 작성하 고 본격적인 예방활동을 추진하게 된다.

특별협약서의 주요 내용은 근골격계질환 예방 및 노동강 도 조정위원회를 구성/운영하고 인간공학 프로그램, 의학적 관리 프로그램의 구축 및 운영을 명시하였으며, 노사합동 산 업재해 상담실 운영을 통해 산업재해자들에 대한 지원을 강
화하기로 하였다. 이러한 모든 내용은 2003년 산업안전보건 법이 개정되기 전에 시행되었으며, 이는 산업안전보건법 개 정에 영향을 미쳤을 것으로 추정된다.

2003년 인간공학 프로그램의 전사확대를 위해 전사 차원 의 조직인 "근골격계질환 예방 위원회"를 구성하고, 각 생산 부서는 "현장개선위원회", "인간공학 담당자"를 조직하여 집 중적인 유해요인의 발굴과 예방활동에 참여하였다. 또한, 인 간공학 담당자, 노동조합 대의원은 16 시간, 현장개선위원회 위원 $(8 \mathrm{H})$, 관리감독자 전원 $(4 \mathrm{H})$ 에게 전문교육(Figure 1)을 실시하였으며, 최고경영자에서 작업자까지 근골격계질환에 대한 유해요인, 징후와 증상, 예방방안, 의학적 관리에 대한 내용에 대해 교육을 실시하였다.

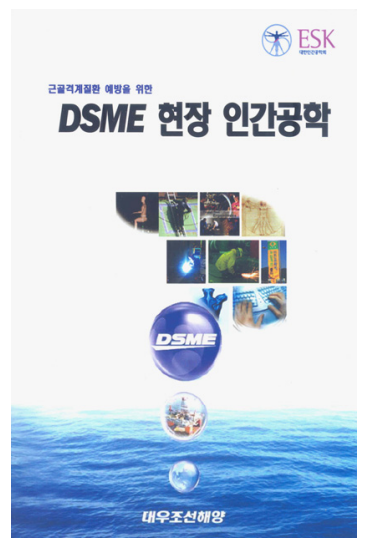

Figure 1. Practical textbook of DSME ergonomics

이와 같이, 2001년부터 시작된 인간공학 프로그램은 2011 년 현재 작업장 개선 중심의 인간공학 프로그램과 증상호소 자에 대한 상담에서 치료 복귀까지의 과정을 명시한 의학적 관리 프로그램을 상호연계하여 운영하고 있다(Table 1).

연도별 인간공학적 작업장 개선 실적으로 보면, 2004년 전사확대 실시 후 매년 평균 607건의 개선활동이 완료되고 있다(Table 2). 또한, 이러한 자료에 대한 벤치마킹 및 실적 분석을 위하여 조선산업(조선업)에 맞는 인간공학적 작업개 선 유형을 크게 6가지 카테고리로 나누고 26가지 세부항목 으로 구성하여 ERP(Enterprise Resource Planning) 시스 템으로 관리하고 있다(Figure 2).

그리고 조선산업(조선업)의 특성상 생산제품과 작업장이 동일하며, 설계로 인한 개선의 제약이 많음에 따라, 설계단 계에서 근원적 예방을 위해 설계원들에 대한 "인간공학 관점 의 설계"에 대해 교육을 실시하였으며, 자동화 장비/설비 개 발을 담당하고 있는 연구소에 대한 교육을 실시하여 전사적 인 차원의 활동으로 확대하였다. 또한, 정적인 작업이 많은 용접작업, 다양한 형태의 의장작업 등을 고려하여 현장, 사 
Table 1. The status of ergonomics program implement

\begin{tabular}{|c|c|}
\hline $\mathrm{ar}$ & Desc \\
\hline $\begin{array}{l}\text { 스터플 } \\
\text { 수립 }\end{array}$ & $\begin{array}{l}\text { - 인간공학프로그램 개발(시범부서 적용) } \\
\text { - 근골격계질환 예방관련 노사 합의 } \\
\text { (특별협약서) } \\
\text { - 임원, 관리감독자 근골격계질환 예방 교육 } \\
\text { 실시 }\end{array}$ \\
\hline $\begin{array}{c}\text { 2003 2004 } \\
\text { 인간공학 } \\
\text { 프로그램 } \\
\text { 구축/실행 }\end{array}$ & $\begin{array}{l}\text { - 근골격계질환 예방위원회, 현장개선 위원회, } \\
\text { 인간공학 담당자 구성 } \\
\text { - 관련 인력 전문 교육 실시(1000 여명) } \\
\text { - 인간공학 프로그램 전사확대 적용(생산부서) } \\
\text { - 프로그램 절차서에 따른 체계적인 예방활동 } \\
\text { 시행 } \\
\text { - 인간공학 프로그램 경진대회 실시 } \\
\text { (우수팀 포상) } \\
\text { - 최초 유해요인조사 실시 } \\
\text { (조사표 3천여건, 설문조사 6천여건) }\end{array}$ \\
\hline $\begin{array}{c}\text { 2005 2006 } \\
\text { 인간공학 } \\
\text { 프로그램 } \\
\text { 활성화 }\end{array}$ & $\begin{array}{l}\text { - 인간공학 프로그램의 Level-Up, 역량강화 교 } \\
\text { 육 및 기술지원 실시 } \\
\text { - 프로그램 분기별 추진 및 HSE 평가 } \\
\text { - 프로그램 Audit 실행, 우수추진 팀 발표 및 } \\
\text { 포상 실시(1회/년) } \\
\text { - 인간공학 프로그램의 협력사 확대 실시 } \\
\text { - 주요 개선사례집 발간(4회/년) } \\
\text { - 팀장/파트장, 설계/연구소 등 근골격계질환의 } \\
\text { 이해 및 현장개선 참여유도 }\end{array}$ \\
\hline $\begin{array}{c}2007 \sim 2009 \\
\text { 현장개선 } \\
\text { 위원회 } \\
\text { 활동 정착 }\end{array}$ & $\begin{array}{l}\text { - 2차 유해요인조사 실시 } \\
\text { (기본조사표 2,558건, 설문조사 6,159명) } \\
\text { - 팀별 개선과제 선정/해결(우수조직 포상) } \\
\text { - 협력사 근골격계질환 예방활동 역량강화 } \\
\text { (정기적 지도/점검) } \\
\text { - 인간공학 프로그램 평가기준 합리화 } \\
\text { - ERP 시스템 내에 인간공학 프로그램 활동 } \\
\text { 구축 }\end{array}$ \\
\hline $\begin{array}{c}2010 \sim \\
\text { 프로그램 } \\
\text { 리모델링 }\end{array}$ & $\begin{array}{l}\text { - 프로그램의 정착 / 자체 평가 및 개선 } \\
\text { - 협력사 근골격계질환 예방활동 표준 모듳 } \\
\text { 정립 } \\
\text { - OHSAS18001 HSE경영프로그램에 반영 } \\
\text { - 경영성과 지표에 반영 관리 } \\
\text { (요양율, 요양일수, 산재율 등) }\end{array}$ \\
\hline
\end{tabular}

Table 2. The number of ergonomics workplace improvement per year

\begin{tabular}{c|c|c|c|c|c|c|c}
\hline Year & 2004 & 2005 & 2006 & 2007 & 2008 & 2009 & 2010 \\
\hline Number & 534 & 718 & 555 & 670 & 769 & 426 & 580 \\
\hline
\end{tabular}

무실, 가정에서 빈번하게 발생하는 동작을 분석 후 작업자세 별 스트레칭을 개발/보급하여 개인의 예방에 대한 관심도 유 도하였다.

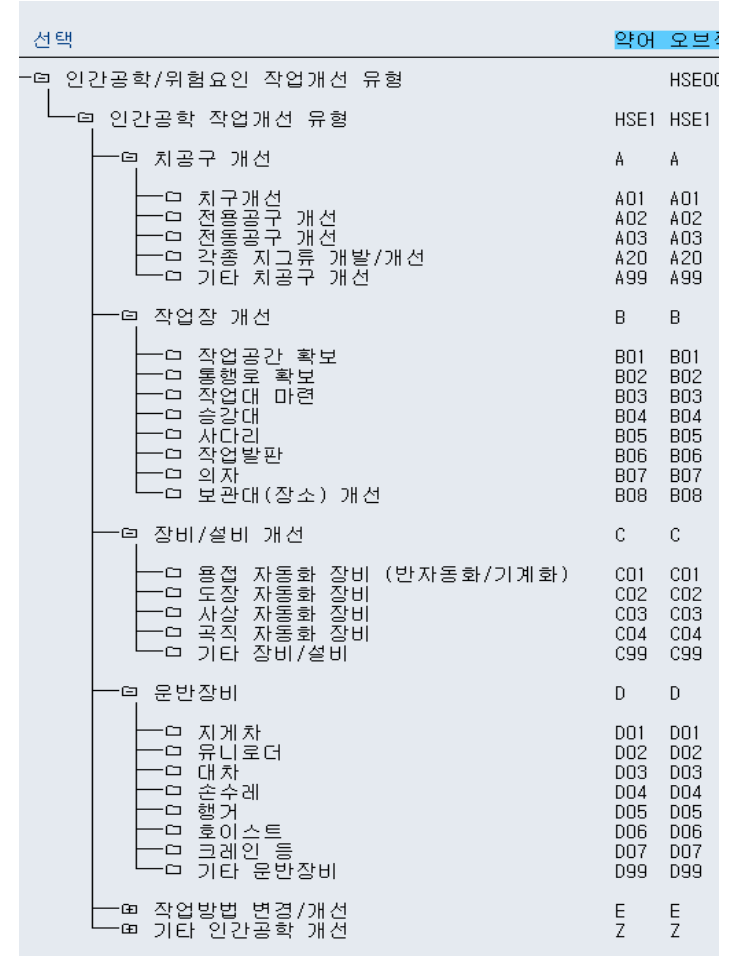

Figure 2. Ergonomics improvement category

의학적 관리 측면에서는, 근골격계질환의 조기치료 및 복 귀를 위해 물리치료실, 운동치료실 확대 및 신규 설치, 사내 체력단련장 설치하였으며, 근골격계질환 통증을 갖고 있는 누구나 쉅게 접근할 수 있도록 근골격계질환만을 전문으로 상담하는 "노사합동 산업재해상담실"을 개설하여 노사가 공 동으로 예방활동 추진하는 발판을 마련하였다. 또한, 근골격 계질환의 발생요인 중의 심리적인 요인에 대해 도움을 주고 자, 산재환자들을 대상으로 심리상담실을 개설하고 전문가를 채용하여 다각적인 방법으로 예방활동을 추진하였다.

\section{The Effects of an Ergonomics Program Implement}

앞에서 살펴 온 봐와 같이 $\mathrm{D}$ 사의 인간공학 프로그램을 주 축으로 한 근골격계질환 예방 프로그램은 지난 10년간 지속 적으로 추진되어 운영 효과는 다음과 같다.

\subsection{Reduction in the incidence of WMSDs}

2000년 이전 근골격계질환자에 대한 데이터는 정확하게 
남아 있지 않으며, 대부분 요통사고 위주로 발생했을 것으로 추측되며, 개인적인 치료도 많이 있었을 것으로 추정된다. 2001년 이후부터는 사회적인 관심이 높아지면서 실질적인 통계관리가 되어 왔다고 볼 수 있을 것이다. Table 3에서 보 는 봐(바) 와 같이 2001년 143건이던 근골격계질환자 발생 건수는 2002년 412건으로 가장 많이 발생하였으며 이후 년 평균 $24 \%$ 정도 지속적으로 감소하였다.

2002 2003년 근골격계질환 발생 건수의 증가는 프로그 램 도입 초기의 유해요인조사, 작업자의 인식 변화, 잠재환 자 발굴, 조기치료 등으로 인한 영향으로 보이며, 이후 프로 그램이 활성화하고 정착단계에 이르면서 지속적인 감소효과 를 보이고 있다.

Table 3. The numbers of WMSDs cases per year

\begin{tabular}{c|c|c}
\hline Year & Number & Reduction rate(\%) \\
\hline 2001 & 143 & \\
\hline 2002 & 412 & -188 \\
\hline 2003 & 336 & 18 \\
\hline 2004 & 240 & 29 \\
\hline 2005 & 159 & 34 \\
\hline 2006 & 96 & 40 \\
\hline 2007 & 76 & 21 \\
\hline 2008 & 66 & 13 \\
\hline 2009 & 70 & -6 \\
\hline 2010 & 39 & 44 \\
\hline
\end{tabular}

\subsection{Reduction in the numbers of patient}

2002 2004년 급증한 산재환자는 예방 프로그램의 구축 이후 2006년에는 2001년 발생 건수 이하로 감소하였으며,

Table 4. The numbers of patient per year

\begin{tabular}{c|c}
\hline Year & Number(person) \\
\hline 2001 & 167 \\
\hline 2002 & 377 \\
\hline 2003 & 442 \\
\hline 2004 & 402 \\
\hline 2005 & 284 \\
\hline 2006 & 147 \\
\hline 2007 & 97 \\
\hline 2008 & 46 \\
\hline 2009 & 50 \\
\hline 2010 & 29 \\
\hline
\end{tabular}

2010년에는 2002년 프로그램 개발 시점 발생자 대비 8\% 수준으로 감소하였다(Table 4).

\subsection{Reduction in the average duration of treatment}

근골격계질환으로 요양 후 복귀자에 대한 평균 요양일수 를 살펴보면 2002년 이후 급증한 환자가 복직하는 2003년 이후 요양일수가 급격히 증가하였으며, 2008년부터 감소추 세에 있다. 하지만 아직도 평균요양일수가 1 년에 가까운 만 큼 개인별 치료기간에 대하여 근로복지공단 및 회사가 더욱 더 관심을 가져야 할 것으로 생각된다(Table 5).

Table 5. The numbers the average duration of treatment per year

\begin{tabular}{c|c}
\hline Year & Number(day) \\
\hline 2001 & 176 \\
\hline 2002 & 195 \\
\hline 2003 & 557 \\
\hline 2004 & 586 \\
\hline 2005 & 628 \\
\hline 2006 & 575 \\
\hline 2007 & 636 \\
\hline 2008 & 497 \\
\hline 2009 & 361 \\
\hline 2010 & 314 \\
\hline
\end{tabular}

\subsection{Reduction in the industrial accident costs}

하인리히의 재해손실비용 모델(재해손실비용 $=$ 직접비 + 간접비, 직접비 : 간접비 $=1: 4$ )에 의하여 한국에서 근골격계 질환으로 인한 1 인당 재해손실비용은 약 1 억 5 천만 원으로 추산된다고 보고하였다(Kim et al., 2002). 그 동안의 물가 상승 분을 고려하지 않더라도 2010년까지의 재해손실비용 을 추정해보면, 2003년 이후 발생자 기준으로 고려해 최근 10 년간 약 560 억 원이 감소한 것으로 보인다. 물론 근골격 계질환자의 감소는 산업안전보건법 등의 예방법규 강화, 사 회적 인식 변화, 산재인정 기준에 대한 검토, 근로복지공단 의 업무상 질병판정 위원회 가동 등의 활동 등도 영향을 미 쳤다고 볼 수 있지만, 가장 중요한 회사내의 예방 프로그램 의 구축과 실행의 효과를 무시할 수 없을 것이다(Kim et al., 2006). 또한, 적극적인 대처와 전방위적인 노력으로 많은 외국사례와 유사한 결과를 보이고 있다. 


\subsection{Reduction in worker's compensation cost}

산재보험료는 매년 6월 30일을 기준으로 과거 3년 동안 의 보수총액에 대한 산재보험급여총액의 비율을 기초로 하 여 정해지며, 업종별 기본요율에 회사별 최근 3 년간의 수지 율을 적용하여 최종 적용요율을 결정하게 된다. 그러므로 최 근 산재보험료 납부의 변화는 단기간의 효과보다는 장기간 의 효과에 대한 판단자료로 활용될 수 있다.

연도별 산재보험료 납부 현황을 보면(Table 6), 2002 2005년 집중적으로 발생한 근골격계질환의 영향으로 2008 년 산재보험료까지 영향을 미친 것으로 알 수 있으며, 2009 년에는 전년 대비 124 억이 감소하였으며, 2010년(전년 대 비 90억 감소) 산재보험료 또한 감소를 보이고 있다.

Table 6. The worker's compensation cost per year

\begin{tabular}{c|c}
\hline Year & Compensation cost(100 million) \\
\hline 2003 & 193 \\
\hline 2004 & 314 \\
\hline 2005 & 258 \\
\hline 2006 & 330 \\
\hline 2007 & 398 \\
\hline 2008 & 428 \\
\hline 2009 & 304 \\
\hline 2010 & 214 \\
\hline
\end{tabular}

\subsection{Reduction in the lost time}

본 사업장의 경우, 2002년 노사 합의된 사항의 일환으로 "노사합동 산업재해상담실"을 운영하고 있으며, 보건관리자 (의사)와의 상담을 통해 근골격계 증상 호소자의 휴업치료, 병원치료 등을 구분하여 관리하고 있으며, 사내치료실을 이

Table 7. The lost time per year

\begin{tabular}{c|c}
\hline Year & Number(time) \\
\hline 2003 & 12,066 \\
\hline 2004 & 58,754 \\
\hline 2005 & 61,049 \\
\hline 2006 & 48,430 \\
\hline 2007 & 39,779 \\
\hline 2008 & 34,073 \\
\hline 2009 & 35,018 \\
\hline 2010 & 32,751 \\
\hline
\end{tabular}

용할 수 있도록 하였다. 사내 물리치료실 이용실적(Table 7)을 보면, 2005년 물리치료실 이용 건수는 총 61,049건 으로 최소 $61,049 \mathrm{M} / \mathrm{H}$ (man hour) 가 유휴 시수로 나타났 으며, 이를 금액으로 환산하면 약 9 억 2천만원 정도이다. 이 것은 물리치료실 방문을 위한 이동/복귀 시간을 제외하고 단 순히 치료받은 시간만을 기준으로 하였으며, 최소 임금기준 $(15,000$ 원 $/ \mathrm{H})$ 을 곱하여 계산한 것이다. 그 후 점차 감소하 여 2010년에는 약 $46 \%$ 감소를 보였다.

\section{Conclusion}

2000년 초반부터 급증한 근골격계질환은 발생 초기에는 제도 및 법규 제정, 동료 작업자 근로의욕 저하, 산업재해 요 양자에 대한 보상문제, 의료비부담, 작업강도 조정 등의 문 제로 많은 어려움이 있었으나, 노사간의 협력을 통해 합리적 인 방안을 찾아내고 인간공학 프로그램과 같은 전 방위적인 예방활동을 통하여 2001년 이전 수준까지 감소시켰다. 이러 한 인간공학 프로그램의 효과는 질환자 감소, 요양일수 감소, 재해손실비용 절감 및 유휴 시수의 감소의 효과에서 확인할 수 있었다. 또한, 인간공학 프로그램을 주축으로 한 예방활 동들을 지표화 하여 회사의 경영성과로서 관리하고 있으며, 조직성과 평가에도 반영하고 있다.

본 사업장은 2005년 인간공학 프로그램 Audit를 진행하 였으며, Audit를 통해 제기되었던 문제점들은 최대한 개선하 여 프로그램을 진행해왔다(Kim and Chang, 2006). 인간공 학 프로그램의 개발의 검토과정에서부터 현재까지의 10 년에 걸친 활동사례를 볼 때 다른 법규 제정, 각종 제도 변화, 질 환에 대한 인식 등이 변화와 더불어 효과는 충분히 입증되 었다. 하지만, 아직도 인간공학 프로그램의 운영에서 필요한 부분은 다음과 같다.

첫째, 조선산업(조선업) 근로자의 고령화는 또 다른 유해 요인이 되고 있다. 2010년 말 기준으로 본 사업장의 경우 생산직 근로자의 $40 \%$ 가 50대로 진입한 만큼, 근력, 지구력, 민첩성이 저하되는 고령자들에 대한 배려가 필요하다. 각 종 표시장치, 작업강도, 작업/휴식시간, 작업표준 재검토, 안 전기준 등 고령자들을 고려해야 할 것이 아주 많다. 이것은 70 80년대 경제발전을 이끈 전통적인 제조업에서는 공통적 인 사항으로 노동부와 산업안전공단의 고령근로자에 대한 대책과 지원이 필요할 것으로 보인다.

둘째, 다른 참고문헌 대부분에서 언급된 설계단계에서의 접근이 필요하다. 조선산업(조선업)에서의 설계는 각종 선 박구조물의 뿐만 아니라, 현장에서 일하는 작업장의 구조도 변경될 수 있다. 이러한 설계 부문의 문제점은 불필요한 작 
업수행 또는 중복작업으로 인한 유해요인 노출 등의 결과 를 가져올 수 있기 때문에 인간공학적인 검토는 매우 중요 하다.

물론, 현재도 각 $\mathrm{TF}$ (Task Force) 활동이나 소위원회 활 동 등에 의해 인간공학적인 문제에 대해 생산조직과 설계조 직이 협력하여 개선활동을 추진하고 있으나, 일부 조직에서 한정된 활동이 아니라 시스템적인 활동이 될 수 있도록 해야 할 것이다.

마지막으로, 2001년부터 현재까지의 기간이 근골격계질환 에 대한 사회적인 인식과 산업재해로서 예방활동의 대상이 고, 인간공학 프로그램의 적용의 시기였다고 한다면 앞으로 의 10 년은 현장작업자를 포함하여 설계, 생산, 공무, 구매, 총무, 안전보건 등 모든 부서의 직무에서 인간공학적인 검토 가 체계적으로 이루어질 수 있도록 적용방법을 개발하고 시 스템화 하여야 한다.

\section{References}

Kim, Y. C., Chang and S. R., "The Effect and Management of the Ergonomics Program for the Prevention of WMSDs in a Shipbuilding Industry", Journal of the KOSOS, 21(6), 2006.

Kim, Y. C., Lee, K. S., Chang, S. R. and Choi, E., J., "Economic analysis of work-related musculoskeletal disorders in Korea", Proceeding 20th anniversary of the founding of the ergonomics society of Korea, 2002.

Kim, Y. C., Lee, J. P., Jeong, H. W. and Chang, S. R., "A study on the effect of ergonomics program", Fall conference of ergonomics society of Korea, 2006.

Kim, H. T., "A study of engineering approach to Musculoskeletal disorders in shipbuilding", Journal of the society of naval architects of Korea,
40(3), 2003.

Kim, Y. C. and Chang, S. R., "A Study of the Implementation of the Ergonomics Program in a Shipbuilding Company", Journal of the Ergonomics Society of Korea, 29(4), 2010.

Pyo, Y. and Jeong, B. Y., "An Implementation Case of Ergonomics Program at a Shipbuilding Company", Journal of the Ergonomics Society of Korea, 26(3), 2007.

\section{Author listings}

Hyun-Wook Jeong: ergonomics@DSME.co.kr

Highest degree: $\mathrm{Ph} . \mathrm{D}$. Candidate, Department of Industrial Management Engineering, Dong-eui University

Position title: Manager, HSE Operation Team, Daewoo Shipbuilding and Marine Engineering

Areas of interest: Ergonomics, Industrial Safety, WMSDs, Job Stress, Human Error

Yu-Chang Kim: yckim@deu.ac.kr

Highest degree: Ph.D., Department of Industrial Engineering, KAIST Position title: Professor, Department of Industrial Management Engineering, Dong-eui University

Areas of interest: Ergonomics, Industrial Safety, WMSDs, Job Stress, Human Error

Date Received : 2012-01-06

Date Revised :2012-01-16

Date Accepted : 2012-01-16 